\title{
Chapter 18 \\ Creating Academic Teacher Scholars in STEM Education by Preparing \\ Preservice Teachers as Researchers
}

\author{
Jennifer Wilhelm and Molly H. Fisher
}

\begin{abstract}
We describe what Research Experiences for Undergraduates (REU) Fellows reported regarding their experiences within a research-intensive programme in STEM Education. Our study employed a mixed methods approach. Quantitative data included a survey by Kardash (2000) to examine Fellows' research expectations, familiarity with literature, and ability to conduct statistical analyses pre and post the interdisciplinary STEM Education programme. We also analysed qualitative data from the Fellows' pre-, mid-, and post-evaluation interviews. We discovered significant growth in their confidence levels in studying, conducting, and analysing research $(p<0.001)$. At the end of their nine- month research experiences, Fellows stated they felt they had gained skills in coding and analysing data, conducting interviews, using technology, writing, and presenting, but most frequently noted their increase of interpersonal collaborations with other future STEM teacher researchers. This research is the first to examine the effectiveness of an academic year interdisciplinary STEM Education REU programme. REU programmes typically are offered two months ( 8 weeks) between Spring and Autumn semesters and within only one STEM content discipline located in schools of science and engineering, as opposed to education.
\end{abstract}

Keywords Mathematics educational research - Science educational research • Undergraduate research experiences · Pre-service teacher education · Pre-service teacher professional development

\subsection{Introduction}

Our novel Research Experiences for Undergraduates (REU) project exposed 23 preservice K-12 science, mathematics, elementary, and special education teachers to

\footnotetext{
J. Wilhelm · M. H. Fisher $(\bowtie)$

University of Kentucky, Lexington, USA

e-mail: molly.fisher@uky.edu

J. Wilhelm

e-mail: jennifer.wilhelm@uky.edu

(C) The Author(s) 2019

B. Doig et al. (eds.), Interdisciplinary Mathematics Education,

ICME-13 Monographs, https://doi.org/10.1007/978-3-030-11066-6_18
} 
timely problems involving STEM teaching and learning through original research conducted with eight successful mathematics and science Education faculty mentors affiliated with the University of Kentucky's STEM Education Department in the United States of America (USA). This project expands the research base concerning undergraduate student research across the disciplines, and serves to inform international efforts towards developing future K-12 STEM educators able to implement research-confirmed pedagogical practices, conduct and respond to authentic research concerning their practice, and serve as agents of change regarding local schooling realities. Our REU project's main objective for pre-service K-12 teachers was to instill an appreciation of the interplay between society, education, and STEM research, that can lead towards improving K-12 students' levels of STEM knowledge and application.

This study aimed to answer the following questions: (1) To what extent can undergraduate STEM Fellows' knowledge and confidence in STEM Education research change through participation in an intensive nine-month research programme? And, (2) What research products, and career trajectories, will result from REU Fellows' participation in our interdisciplinary STEM Education programme?

We designed, implemented, and researched, the effectiveness of our current REU Site project at the University of Kentucky (UoK). Our project: (1) expanded research efforts into novel phenomena in K-12 STEM Education, (2) delivered quality STEM education via Fellows' and faculty mentors' research, and outreach activities, embedded within authentic interdisciplinary STEM formal and informal environments, and (3) created a cadre of educators poised to teach mathematics and science effectively, appreciate the interdisciplinary nature of STEM phenomena, research their practice, and serve as leaders in STEM education at the elementary, middle, and secondary school levels.

\subsection{Background and Literature}

STEM is no longer simply an acronym for Science, Technology, Engineering, and Mathematics, but also a unification of the disciplines that, as an entity, is much greater than the sum of its parts. The field of STEM educational research is ripe with potential for exploration of issues across these disciplines, in high synergy with one another, in terms of the importance of student learning and citizen participation. The barriers towards these things is now of great concern to many, as the USA continues to fall in its international economic competitiveness (Committee on Science, Engineering, and Public Policy, 2006). The under-preparation of the USA's workforce, with respect to STEM knowledge and skills, is a very real problem to remedy, especially when one considers the performance of USA school children across the STEM disciplines, compared to their international peers. The 2006 PISA, which examined 15-yearolds from 57 countries, showed average performance of USA students in terms of scientific concept recall (level 1) and significantly below average performance regarding understanding and application of mathematical and scientific concepts 
(levels 2 and 3). In contrast, Canada (a neighbouring country) ranked in the top 5 in all three categories (OECD, 2007). The 2012 PISA results showed a similarly bleak picture. Students in the USA performed below average in mathematics in 2012, ranking 36 out of 65 countries and economies participating in PISA. USA students performed near average in both reading and science, ranking 23rd in reading and 28th in science (OECD, 2014). For the 2015 PISA results, USA reading and science scores remained relatively the same as the 2012 scores; however, the USA dropped 11-points in the average mathematics score causing the USA to rank 38 th out of 70 participating countries and economies (OECD, 2016).

Equally depressing are postsecondary students' performance with respect to mathematics and science understanding and application (Committee on Science Engineering and Public Policy, 2006; US Department of Education, 2006; US Office of Science and Technology Policy, 2006). Kentucky ranked 49th in the USA in 2003 for bachelor's degrees in science or engineering conferred (Kentucky STEM Task Force, 2007). Our project's ultimate goal is an improvement of K-12 students' levels of STEM knowledge and application, especially for students from historically disadvantaged groups, who enter universities with an especially negative stance towards STEM and their ability to participate in STEM (Clewell, Anderson, \& Thorpe, 1992; Gatta \& Trigg, 2001). The creation of a larger and better-prepared K-12 mathematics and science teacher population is our main strategy towards meeting our goal.

Our REU site, the UoK STEM Education Department, is uniquely positioned at a research university. Our REU research activities are united by their applicability to real-world pedagogical problems in actual STEM learning environments. Poised to train the next generation of teacher researchers are the eight full-time mathematics and science education faculty researchers. Our faculty represents diverse, but overlapping, research agenda, linked by an interest in STEM education that focus on a variety of content areas (mathematics, physics, Earth/space, chemistry, and engineering) as well as all levels of K-20 education. Our collective work explores the multiple means of encouraging effective, deep STEM learning, emphasizing the interdisciplinary ways of understanding physical phenomena, and creating active research participation in STEM by K-20 learners through quantitative, qualitative, and mixed methodologies. With our faculty serving as their mentors, REU Fellows gained experience with current educational issues, understanding of unifying conceptual ideas, and methodological strategies underlying STEM educational research (including its applicability to real-life scenarios), and awareness of the links between society and schooling.

Our REU project redefines the focus of STEM teacher preparation towards the development of students' higher order thinking skills, and deep conceptual STEM understanding, based on research-confirmed best practices discovered by the preservice teachers themselves. Our basic pedagogical approach centres on the active participation of Fellows in authentic inquiry into local educational issues, with national and international implications. Undergraduate participants are engaged in activities that research has demonstrated to be most important with respect to undergraduate research, including reviewing pertinent scholarly literature, developing testable and timely hypotheses and associated empirical tests, gathering and evalu- 
ating related data, and communicating their research to others (Landrum \& Nelsen, 2002; Lopatto, 2003; Sabatini, 1997). Previous research has shown that undergraduate research programmes can allow students to make a more educated decision regarding the pursuit of a graduate degree (Willis, Krueger, \& Kendrick, 2013). Additionally, Kardash (2000), found that female interns in undergraduate research experiences showed less confidence in certain aspects of research than male interns. In the predominantly female field of education, this type of research can be crucial in order to gain more females in STEM fields as "mastery of skills predicts efficacy beliefs, which in turn predicts career aspirations" (Adedokun, Bessenbacher, Parker, Kirkham, \& Burgess, 2013). More confidence in both the areas of STEM content and STEM educational research, for teachers of mathematics and science, should lead to a better prepared student population. Our REU programme is unique, since it extends throughout an academic year, as opposed to the typical 8-week programme that occurs between a Spring and Autumn semester. In addition to this, our programme emphasizes and creates interdisciplinary STEM experiences as Fellows learn, teach, and research STEM content.

\subsection{Participants}

During a three-year period, we recruited 23 highly committed undergraduate students as Fellows, who functioned as a cohort within the larger dynamic of our STEM educational research community. The Fellows represented a diverse group of undergraduate students studying elementary, middle, and secondary level mathematics and science education. In the first cohort, our student demographics were the most diverse with three African-American students (two of whom were "non-traditional" students in terms of age), five White students, one male (which is not a surprise for a programme housed in a College of Education in which the students are predominantly female), five secondary STEM Education majors (four mathematics and one science), two elementary education majors, and one middle level mathematics education major. The second cohort was the least diverse, with eight White female students, in which four were secondary mathematics education majors and four were elementary education majors. The third cohort consisted of one male, one Hispanic student, seven White students, three secondary mathematics education students, three elementary education students, and two special education students. The third cohort included one Fellow from the previous cohort who returned to the programme for a second iteration, thus, the reason for 23 total Fellows. The inclusion of Fellows from major programmes, that are not specifically a STEM content based area, allowed the programme to spread awareness of STEM educational research beyond just students in our department, and has the potential to have an impact on the Fellows' STEM content and pedagogy, while undergraduate students, and in their future classrooms. 


\subsection{Programme Description}

Throughout the programme, Fellows worked in pairs. Each pair was mentored, by one to three faculty researchers (for researchers working on common projects) in the Department of STEM Education (one additional mentor was from an off-site institution). Fellows met with their mentors weekly in Autumn and Spring for 1-3 $\mathrm{h}$ to discuss the progress of their research projects, ask questions emerging from the research procedures, and determine the subsequent research tasks. When mentors, or mentees, could not attend the meeting in person, or on campus, virtual reality, or remote communication tools, were used in order to proceed with the meetings. Most of the Fellows viewed these meetings as great opportunities to develop understanding about their research projects, through interacting with their mentors, graduate students, and their peers. In addition to weekly meetings with their mentors, the Fellows participated in a weekly seminar with the other Fellows. Fellows were interviewed by the project evaluator at the beginning, middle, and end of their experience.

\subsubsection{Individualized Research Projects}

Fellows, in groups of two, worked on individualized research projects under the direction of their faculty mentor(s) conducting research of interest to the Fellows. Fellows met weekly with faculty mentor(s) during the Autumn and Spring semesters. Discussions and work between fellows and mentors were guided by a set of research activity guidelines developed by the Principal Investigator and Co-Principal Investigator to ensure that all projects were progressing efficiently, and that all Fellows' metacognition about STEM Education research was normalized, to some degree, across the cohort. Fellows worked with their mentors on conducting a review of literature, securing IRB approval, developing their hypotheses and empirical tests (Autumn), data collection (Autumn and Spring), and analysis and presentation (Autumn and Spring). Presentations of findings included students' preparation of research talks, posters, and papers, to be presented at their cohort seminars, and at both the Student Research Conference as well as one other research conference with their faculty mentors. Fellows and faculty mentors were also encouraged to submit for publication, at least one article to a practitioner, or research journal. Four projects were conducted each year (with two Fellows per project). Below is a sample of four student projects that illustrates the Fellows' research as well as the interdisciplinary nature of the STEM content that was analysed-including spatial visualization in Earth/Space science, computer programming, and engineering design within a robotics laboratory, mathematical experiences that affect STEM attitudes and beliefs, and the unique ways of attending, interpreting, and deciding within STEM classrooms:

- Exploring variables that affect students' scientific and spatial understandings as they engage in Earth/Space science: This research examined the differences between groups of middle school students' spatial and scientific reasoning from 
pre- to post-implementation of an Earth/Space unit. Using a quasi-experimental design, researchers explored how instructional methods and sex affected learning. Treatment teachers employed a project-based curriculum while control teachers implemented a traditional Earth and Space unit. A Lunar Phases Concept Inventory (LPCI; Lindell \& Olsen, 2002), the Geometric Spatial Assessment (GSA; Wilhelm, Ganesh, Sherrod, \& Ji, 2007), and the Purdue Spatial Visualization TestRotation (PSVT-Rot; Bodner \& Guay, 1997) were used to assess learning. To gain a deeper understanding of students' spatial-scientific reasoning, lessons related to the Earth/Space unit were video-taped and students participated in video-recorded clinical interviews. Interviewees were selected purposefully, based on their highest and lowest scores on the LPCI from pre- to post-test, allowing researchers to examine high and low performing students' spatial development and scientific understandings of lunar phases by sex within, and between, control and experimental groups. This is the first known study that investigated the spatial skills of low and high performing students before, during, and after an Earth/Space unit. REU Fellows participated in data collection and analysis at various levels, including the classroom observations, test administration, clinical interviews, video-taping, transcribing, and analyzing, qualitative and quantitative data. Fellows were mentored on designing an interview protocol that examined how middle school students reason, negotiate the subject matter, and apply learned concepts to new situations. Fellows independently conducted the interviews, transcribed, and analysed results.

- Informal learning environments in STEM education: This project examined the effect of an informal STEM learning environment on middle grades students. The STEM informal learning environment, in this project, was designed to address the inequities of under-represented populations (females and students of colour) experience in formal learning settings, with an underlying goal to increase students' interest and motivation to learn interdisciplinary STEM content, and participate in STEM-related activities. Interdisciplinary learning experiences included robotics, which purposefully integrated computer programming and engineering design. Research Fellows coded and analysed written survey responses obtained from students after the conclusion of their informal experience. These data indicated an increase in students' interest in STEM, and an appreciation of the authentic STEM activities that permitted the students to feel like an engineer, scientist, and, or, mathematician.

- Using the Mathematics Experiences and Conceptions Survey (MECS) to understand pre-service Elementary teacher's attitudes and beliefs towards STEM: This work comprised analyses of data from the Mathematics Experiences and Conceptions Survey (MECS; Jong, Hodges, Royal, \& Welder, 2015) designed to understand the evolution of pre-service elementary teachers' attitudes, beliefs, and dispositions towards mathematics and applied mathematics in teaching and learning. Two characteristics that make the surveys particularly powerful are that they: (1) are designed to measure conceptions longitudinally, and (2) collect extensive demographic information, along with items about the pre-service teachers' past experiences as learners of mathematics. The Fellows coded open- ended responses, and learned about descriptive statistics to examine demographic data collected 
on the pre-service teachers. The qualitative and quantitative analyses were both completed using data analysis software that provided the Fellows with essential research skills to develop codes that informed patterns of themes based on frequencies. They found that pre-service teachers attributed STEM teaching success to the following three factors: differentiating instruction, creating engaging lessons with purposeful tasks, and creating a positive classroom community.

- Professional noticing of STEM thinking: Professional noticing is the study of investigating what teachers notice and attend to in classroom situations, how they interpret this information, and what they decide and prescribe as next steps in assisting students in moving forward in their STEM learning (Jacobs, Lamb, and Philipp, 2010). This project consists of a multi-institutional collaborative working towards refining pre-service teachers' practices in STEM education contexts. Specifically, this project involves the creation of focussed course materials (including technology-mediated resources) aimed at the development of professional noticing capacities, and study of pre-service teachers' growth in such dimensions. Fellows participating in this project collected, and analysed, data from other preservice teachers participating in a professional noticing instructional module focusing on STEM professional noticing skills. This project was carried out multiple years in varying capacities with different Fellows participating each year. The data collected included analysis of written responses measuring pre-service teachers' professional noticing skills, scoring and analyses of content knowledge changes within the semester when the instructional module was taught, and interviewing former pre- service teachers that participated in the module and who are now classroom teachers. Fellows found that teachers retained their knowledge in professional noticing when teaching STEM content in their own classrooms, despite the fact they may not remember the exact terminology of the professional noticing construct. In terms of content knowledge, pre-service teachers were found to have increased in some aspects of their content knowledge, especially when trying to explain a child's thinking on certain problems.

\subsubsection{Methods}

We examined the following research questions: (1) To what extent can undergraduate STEM Fellows' knowledge and confidence in STEM educational research change through participation in an intensive nine-month research programme? (2) What research products, and career trajectories, will result from REU Fellows' participation in our interdisciplinary STEM education programme?

This research employed a mixed methods approach (Creswell \& Plano Clark, 2007): (a) Quantitative data included administering a pre- and post-survey with a Likert scale (Kardash, 2000) concerning undergraduate research, to determine Fellows' research expectations, familiarity with research literature, and ability to conduct statistical analyses, and (b) Qualitative data was comprised of the Fellows' pre-, mid-, and post-evaluation interviews, as well as their final research projects, papers, 
Table 18.1 Examples of Survey Questions (Kardash, 2000)

\begin{tabular}{l|l}
\hline Type of question & Example questions \\
\hline "To what extent can you... (24 Questions) & $\begin{array}{l}\ldots \text { write a research paper for publication in } \\
\text { the field of education? } \\
\ldots \text { analyse data statistically in the area of } \\
\text { research you are working on in this } \\
\text { programme? }\end{array}$ \\
\hline "To what extent do you feel this internship will & $\begin{array}{l}\ldots \text { identify a specific question for } \\
\text { investigation based on the research in the } \\
\text { help you... (23 Questions) } \\
\ldots \text { observe and collect data in the field of } \\
\text { education? }\end{array}$ \\
\hline Other (6 Questions) & $\begin{array}{l}\text { I have the ability to have a successful career } \\
\text { as a STEM educator } \\
\text { I possess the motivation and persistence } \\
\text { required for a career as a STEM educational } \\
\text { researcher }\end{array}$ \\
\hline
\end{tabular}

and presentations. Questions on the Kardash (2000) survey included items having to do with Fellows' beliefs concerning how well they felt they understood concepts in the field of education, and in their area of research, and how skilled they felt about making use of scientific research literature in the field of education, and in their area of research (see Table 18.1). Qualitative interviews included questions regarding how well, and in what ways, the REU programme advanced Fellows' STEM Education research knowledge, and had an impact on their future teaching in the areas of mathematics and, or, science.

\subsection{Results and Discussion}

Using a two-tailed t-test to analyse the results of the quantitative survey, we discovered significant growth in the Fellows' confidence levels in studying, conducting, and analysing research. This growth was also echoed in their interviews with the programme evaluator. Further, our findings showed Fellows entered the programme with confidence in analysing literature, but still needed improvement in the areas of designing their own research projects, and performing statistical analysis of their research data. Despite their initial confidence, Fellows believed this programme would increase, greatly, their abilities to conduct research and write manuscripts for publication. At the end of their nine-month research experiences, Fellows stated they felt they had gained expertise in coding and analysing data, conducting clinical interviews, using technology, writing, and presenting, but, most frequently, they noted the increase of interpersonal skills and collaboration with peers. Table 18.2 shows the results of $\mathrm{t}$-tests for each year of the programme, as well as a combined test of all cohorts. While some may quibble over the use of a t-test in lieu of a non- 
Table 18.2 t-table with pre- and post-programme changes by cohort and combined ${ }^{\mathrm{a}}$

\begin{tabular}{l|l|l|l|l}
\hline & Pre & Post & Change & Significance \\
\hline Year 1 & 4.11 & 4.48 & 0.37 & $t(7)=-2.805, p=0.026$ \\
\hline Year 2 & 4.10 & 4.36 & 0.26 & $t(7)=-2.096, p=0.074$ \\
\hline Year 3 & 4.08 & 4.47 & 0.39 & $t(5)=-2.612, p=0.048$ \\
\hline Combined & 4.10 & 4.44 & 0.34 & $t(21)=-4.488, p<0.001$ \\
\hline
\end{tabular}

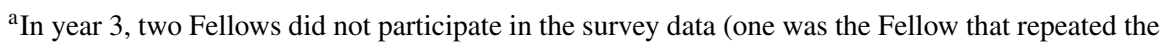
programme)

parametric test, de Winter and Dodou (2010) found no difference between a t-test and a non-parametric Mann-Whitney-Wilcoxon test when using five-point Likert data.

\subsubsection{Fellows' Beliefs Concerning Stem Education Research}

The REU programme clearly influenced students' beliefs about educational research. When they were asked about their views on educational research in pre-programme interviews, no Fellow mentioned the importance, or nature, of educational research: however, Fellows' view on educational research went much deeper by the middle and end of their REU experiences. During the mid-point interviews, the Fellows began to express the view that they realized educational research is highly important as educational research improves knowledge of instructional methods, and helps to make informed educational decisions. Excerpts highlight the points as below.

(Excerpt 8: mid-interview)

Interviewer: what is your current view on educational research? Fellow: That's real important. I think that education is something that is not seen as high as, for example, some type of science research, but actually I think it is as important, especially since there's a lot of reform with education, like what's best ... so I think research really helps to decide what the best thing to do for education is and how to reform it. It's constantly changing.

(Excerpt 9: mid-interview)

I believe it's to make the whole process of education for both teachers and students a more productive experience ... enhancing education on both sides. That's what I see educational research as ... just making the whole institution of education better.

At the end of the year-long experience, the Fellows expressed that they realized (1) a great number of interdisciplinary topics can be studied in STEM education, (2) it is very important for teachers to keep up with the current educational studies to improve their teaching, and (3) it is possible for teachers to conduct educational research even though it is not easy. An example follows:

(Excerpt 10: post-interview)

I think it's really important. Like, as a nation we have so many different ideas as to what is the best way to teach students, and there are so many different learning styles that are prevalent 
now that weren't even thought of maybe 20 years ago. I think it's really interesting to keep finding out the ways students learn because school is ... You know, the majority of their lives growing up they spend so much of their time there and then pursue higher education, and kids can spend up to 10 to 12 years in school. So it's really important to keep researching, and keep understanding how students learn, how we can teach better ... it's really important. Sometimes it's harder because it's educational, so it's a lot of observing in classrooms, it's a lot of transcribing interviews, it's not like a scientific thing where you administer this and then you jot down the data, and the numbers will give you your answer. So it takes a lot more of an "analysational" approach, and it's harder and it's longer, but I think it's definitely really important."

\subsubsection{Student Skills of Education Research}

To assess the change in Fellows' skills of educational research, students were asked to rank their research skills and abilities in both pre- and post-surveys using a Likert scale ranging from "No skills and ability (1)" to "Great skills and ability (5)." During the final phase of the project, the same questions were given to a control group (nonparticipant students from another educational course) of similar size as our final REU cohort. The Fellow completing her second year was excluded from this analysis to maintain data consistency. Fellows' skills were assessed on the following aspects: (a) Thinking and working like a researcher, (b) Personal gains related to research work, (c) Research skills, and (d) Attitude and behaviours as a researcher.

Nine statements were used to assess students' gains within the "Thinking and Working like a Researcher" aspect and those statements were examined more closely. At the end of the year-long experience, all final cohort Fellows indicated that they possessed good skills, and, or, abilities with respect to all nine statements. Of these aspects, Fellows significantly gained in (1) identifying limitations of research methods and designs, (2) understanding the theory and concepts guiding educational research, and (3) formulating a research question that could be answered with data. Results indicated that they gained the least in understanding how educational research projects connect to the broader teaching challenges in the field and problem-solving in general. The limited gains were due, most likely, to Fellows' high confidence in these aspects at the programme's beginning. Compared to the control group students, Fellows possessed high level skills and abilities in all nine aspects as shown in Fig. 18.1.

\subsubsection{Impact on Fellows' Future Teaching}

Fellows' responses to the post-survey suggested the REU experience did not significantly change their career goals. Most of the Fellows still planned to work as a teacher at the K-12 level. However, the post-interview suggested the experience had helped students gain deep pedagogical knowledge, and strategies, that could be integrated into their future STEM teaching. The experience also had a strong influence 


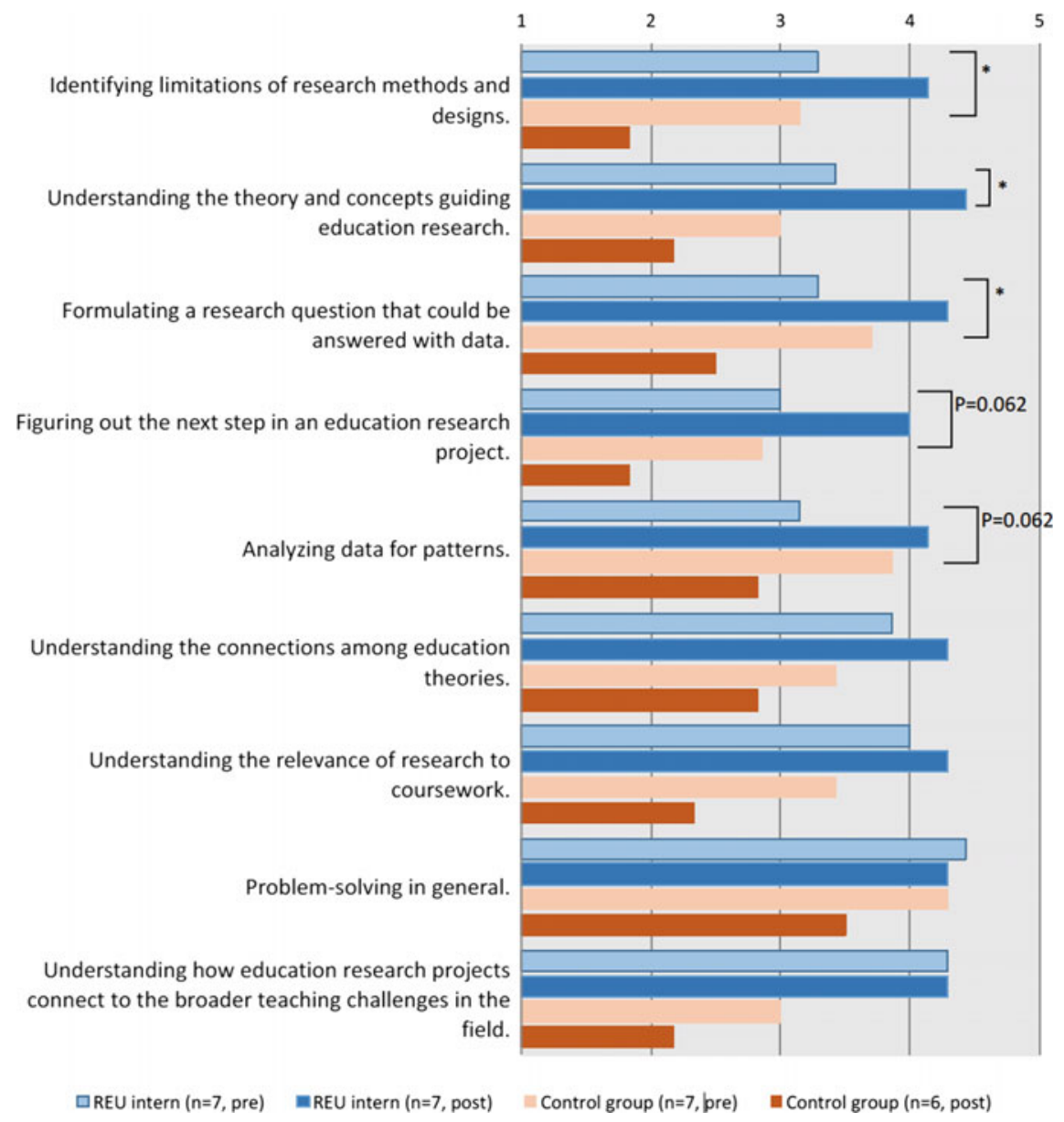

Fig. 18.1 Gains in thinking and working like a researcher $\left({ }^{*} p<0.05\right)$

on Fellows' perspective on their teaching career, and motivated them to conduct their own research as a teacher. As two Fellows noted in the post-interview:

(Excerpt 13: post-interview)

Our specific research was about a type of pedagogy, and so I think that I am very ... I'm pretty much an expert on that subject now after all of the things that I've read. So I think that I could probably use that in my classroom, and then again my experience will help me with my research - knowing which types of research I want to do, how to go about it, what type of interview I want to do, so just getting that information from the programme will be beneficial in the future because I probably want to do it myself.

(Excerpt 14: post-interview) 
I don't plan on doing anything STEM necessarily. But it has given me, I guess, a better perspective on teaching and what all goes into that, especially with professional noticing in the classroom. So it's been interesting.

In the mid-point interview, the Fellows were asked to compare the REU experience to the regular education classes. All Fellows expressed that they gained more from their REU experience than the regular classes, specifically in the following ways:

(i) Gained deeper insight and understanding about the knowledge taught in regular class by actively doing research:

(Excerpt 19: Mid-point interview)

I just feel like I have a better insight, like I have more knowledge about things that kind of just get talked over in regular classes. Like I have more in depth understanding about things. Like the other day in one of my classes we talked about professional noticing, but it was brought up very ... it's just like, almost like one day in class and then for teaching it's like now that I know all about it I feel like it's one of the best things you can do for a classroom. So I feel like that should be more of a thing. It's almost ... it is a thing ... in all the regular ed classes they talk about the strategies that you can use and stuff like that, but this is something that like ... like strategies, like worksheets, and things to do in the classroom ... but this is something that if you start doing professional noticing you'll start to be a better teacher more so than just having all the paperwork ready. You'll be able to teach well, teach better off.

\section{(Excerpt 20: Mid-point interview)}

It's just way more hands-on, you can actually see it yourself rather than just reading it from a textbook and someone else kind of telling you what the research is. When you are doing it yourself you can ... you're actually in the depth of it, and you are ... it just helps you get more knowledge and more personal experience with the subject ... whatever it would be.

(ii) Gained new perspective on teaching methods:

(Excerpt 21: Mid-point interview)

I think it helps you see teaching in a different way. Like when you're in your normal classes, you see teaching from observing an actual teacher; and doing the research you see ... you get to see so many studies done on teachers in their classrooms, and you get to see the background ... like more technical side of teaching than just observing a classroom. So, like you learn about the research behind pedagogical strategies and things like that that can really benefit you more than just watching someone teach and not having like these terms and the research to backup if that's good or bad.

(iii) Gained understanding about practice and school atmosphere:

(Excerpt 22: Mid-point interview)

I feel like I've gained so much more understanding about how students learn and think, and then definitely this air of professionalism going into schools, working with teachers, communicating with them regularly ... I feel like I'm sort of on their level as opposed to like just a student coming into watch their class. So it's definitely given me a lot of experience other than just that passively sitting in the back of the room, taking notes and stuff. 
The overall productivity level of the Fellows in the project has been astonishing. To date, REU Fellows involved in this programme have participated in fifteen research presentations, and have co-authored nine manuscripts (that are printed or in press) in journals such as School Science and Mathematics and Science Scope, with many other manuscripts currently under review, or under revision, for a journal. The accolades of the Fellows do not end with scholarship in terms of presentations and publications. Four Fellows have been awarded summer research grants to continue their work, one was offered a summer position teaching for a prestigious summer programme at Duke University, three entered graduate programmes with fully funded research positions (one Master's programme and two doctoral programmes), one worked as a pre-service teacher summer research Fellow for Pearson, and another went on to participate in a summer REU experience at another research university after leaving her academic year REU programme at UoK.

One of the Fellows, from the first cohort, summed up her experience with the following:

I definitely think about research differently from what I did before. Before it was like this intangible thing and too hard. But actually getting involved and doing it was a really great experience. It also was seeing the importance of doing the research and looking at the results and how those can be used in the classrooms and how that is beneficial to the education community in general.

Although, their ultimate career goal of becoming a mathematics or science teacher did not change, five of the Fellows did choose a trajectory that included additional research experiences in the area of STEM, and three of the Fellows went on to pursue graduate degrees prior to becoming classroom teachers.

\subsection{Conclusion and Coda}

As shown in both the quantitative and qualitative data, STEM Fellows' knowledge and confidence in STEM educational research increased. Research projects were numerous and included conference presentations and publications. Similar to Willis et al. (2013), our programme allowed the Fellows to make more educated decisions regarding pursuing graduate degrees and embarking on new research endeavours.

Our study added to the Kardash (2000) study in several ways. Kardash noted female REU interns tended to show less confidence in research skills than their male counterparts. Our research found females improving in their research skills in multiple areas, giving them the ability to be, not only more effective teachers, but also, more effective teacher researchers. Perhaps being female REU Fellows in a predominantly female field, such as education, might have helped with their confidence. Kardash claimed that one of the limitations of her study was the lack of a control group. During the final phase of our interdisciplinary STEM Education programme, a control group (non-participant students from another education course of similar size to our REU cohort) was added. Fellows' gains on thinking and working 
like a researcher, were higher than that of the control group especially in the areas of (1) identifying limitations of research methods and designs, (2) understanding the theory and concepts guiding educational research, and (3) formulating a research question that could be answered with data.

While this study does build upon the findings of Kardash (2000), it also has many differences. Most notably, the Kardash study focussed on a group of student interns majoring in science fields. These students spent research hours in a science laboratory conducting research in areas such as biology, biochemistry, chemistry, and physics. Fellows, in our present study, were participating in social sciences research with human subjects, which had STEM content embedded in the research projects. Additionally, Kardash used groups of Fellows from two very different undergraduate research experiences. Of the 57 interns studied, nineteen were from an academic year programme in which the students worked twelve hours per week and the other 38 Fellows were from a Summer (two month) programme in which the students worked $40 \mathrm{~h}$ per week in the science laboratories.

We recognize that there are limitations to our study as well. Mostly, the sample size of eight interns per year, is small, and could contribute to possible statistical errors. Also, with the 23 Fellows being assigned to eight different faculty mentors throughout the course of the three-year project, the Fellows were afforded a variety of research experiences. Most Fellows participated in qualitative research, but a few participated in quantitative and mixed methods research. While not entirely a limitation, the diversity in experiences meant that some Fellows did not get as much practice across the different types of research methodologies. On the other hand, this allowed for more fruitful and diverse discussions during the class meetings of the Fellows, as they discussed their progress in their research projects.

This REU project is original and unique, as it is one of the first where participating students are preparing to be K-12 teachers, as opposed to preparing for a career in a STEM field. In addition, this REU project was enacted during the academic year, whereas most REU opportunities occur during the two-month Summer break. Working with the Fellows during the academic year provided opportunities for Fellows and their mentors to conduct their research in formal and informal educational settings with human subjects. Our STEM Education faculty represent diverse, but overlapping research agenda, linked by an interest in interdisciplinary STEM education that includes motivation and career trajectories for STEM educators in K-12 and higher education, issues of racial and sex equity, how to increase participation and connection-making in K-12 mathematics and physical sciences, and implementation of technology, and engineering concepts, and tools that unite, and help teach, across STEM content areas. Our work explored, collectively, the multiple means of encouraging effective deep STEM learning, and active participation in STEM content, by K-20 learners through quantitative, qualitative, and mixed methodologies. With the STEM Education faculty serving as their mentors, REU Fellows gained experience with particular educational problems, broad understanding of unifying conceptual ideas, and methodological strategies, underlying STEM educational research (including its applicability to real-life scenarios), and awareness of the links between society 
and schooling. Future research with REU Fellows will include determining how the Fellows' research experiences influenced their teaching and classroom practices.

Our interdisciplinary STEM research programme can inform anyone that is working with undergraduate researchers, even those working in shorter time periods, and not working with human subjects as our projects have. This programme has now created 31 teacher researchers in four cohorts of Fellows. Through social media, and other measures, we have managed to stay in contact with the majority of the Fellows. Many of them have re-iterated the importance of our programme and how their knowledge has translated to their classrooms. Now that many of the previous Fellows have graduated and started their professional careers, our future plans involve reunions with the Fellows to discuss their current professional status, and what the REU programme has changed about how they approach their careers and in what ways it has influenced their K-12 students.

We invite researchers (including teacher researchers) to join us in debating what interdisciplinary mathematics is, and how, or if, it is any different than interdisciplinary STEM. We call on you to follow our STEM Education Department at the University of Kentucky (USA) as we model and visualize the natural world, engineer better lives for K-12 students, and study all those mathematical experiences that shape interdisciplinary STEM attitudes, notions, and beliefs. We are situating ourselves with the future interdisciplinary teacher researchers of the world.

Acknowledgements This research was supported by the National Science Foundation (NSF project \# 1156848).

\section{References}

Adedokun, O. A., Bessenbacher, A. B., Parker, L. C., Kirkham, L. L., \& Burgess, W. D. (2013). Research skills and STEM undergraduate research students' aspirations for research careers: Mediating effects of research self-efficacy. Journal of Research in Science Teaching, 50(8), 940-951.

Bodner, G. M., \& Guay, R. B. (1997). The Purdue visualization of rotations test. The Chemical Educator, 2(4), 1-17.

Clewell, B. C., Anderson, B. T., \& Thorpe, M. E. (1992). Breaking the barriers: Helping female and minority students succeed in mathematics and science. San Francisco: Jossey-Bass.

Committee on Science, Engineering, and Public Policy. (2006). Rising above the gathering storm: Energizing and employing America for a brighter economic future. Washington, D.C.: National Academies Press.

Creswell, J. W., \& Plano Clark, V. L. (2007). Designing and conducting mixed methods research. Thousand Oaks, CA: Sage.

de Winter, J. C. F., \& Dodou, D. (2010). Five-Point Likert items: t test versus Mann-WhitneyWilcoxon, Practical Assessment. Research and Evaluation, 15(11).

Gatta, M., \& Trigg, M. (2001). Bridging the gap: Gender equity in science, engineering and technology. New Brunswick, NJ: Center for Women and Work, Rutgers University.

Jacobs, V. R., Lamb, L. L. C., \& Philipp, R. A. (2010). Professional noticing of children's mathematical thinking. Journal for Research in Mathematics Education, 41, 169-202. 
Jong, C., Hodges, T., Royal, K., \& Welder, R. (2015). Instruments to measure elementary preservice teachers' conceptions. Educational Research Quarterly, 39(1), 21-48; Social Science Premium Collection.

Kardash, C. (2000). Evaluation of an undergraduate research experience: Perceptions of undergraduate Fellows and their faculty mentors. Journal of Educational Psychology, 92(1), 191-201.

Kentucky STEM Task Force. (2007). Kentucky's STEM imperative: Competing in the global economy. Frankfort, KY: Council on Postsecondary Education STEM Task Force Report.

Landrum, R. E., \& Nelsen, L. R. (2002). The undergraduate research assistantship: An analysis of the benefits. Teaching of Psychology, 29(1), 15-19.

Lindell, R., \& Olsen, J. P. (2002). Developing the lunar phases concept inventory. American Association of Physics Teachers Summer Meeting (Physics Education Research Conference).

Lopatto, D. (2003). The essential features of undergraduate research. Council on Undergraduate Research Quarterly, 23(1), 139-142.

OECD. (2007). PISA-2006 Science competencies for tomorrow's world, 1 (analysis). Paris: OECD.

OECD. (2014). PISA-2012 Results: What students know and can do-student performance in mathematics, reading and science (Revised Edn., Vol. I, February 2014), PISA, OECD Publishing.

OECD. (2016). PISA-2015 Results in focus. Paris: OECD Publishing.

Sabatini, D. A. (1997). Teaching and research synergism: The undergraduate research experience. Journal of Professional Issues in Engineering Education \& Practice, 123(3), 98.

U.S. Department of Education. (2006). Meeting the challenge of a changing world: Strengthening education for the 21 st century. Washington, D.C.: U.S. Government Printing Office.

U.S. Office of Science and Technology Policy. (2006). American competitiveness initiative: Leading the world in innovation. Washington, D.C.: U.S. Government Printing Office.

Wilhelm, J., Ganesh, B., Sherrod, S., \& Ji, J. (2007). Geometric spatial assessment. Developed at Texas Tech University (modified in 2012).

Willis, D. A., Krueger, P. S., \& Kendrick, A. (2013). The influence of a research experiences for undergraduates program on student perceptions and desire to attend graduate school. Journal of STEM Education, 14(2), 21-28.

Open Access This chapter is licensed under the terms of the Creative Commons Attribution 4.0 International License (http://creativecommons.org/licenses/by/4.0/), which permits use, sharing, adaptation, distribution and reproduction in any medium or format, as long as you give appropriate credit to the original author(s) and the source, provide a link to the Creative Commons licence and indicate if changes were made.

The images or other third party material in this chapter are included in the chapter's Creative Commons licence, unless indicated otherwise in a credit line to the material. If material is not included in the chapter's Creative Commons licence and your intended use is not permitted by statutory regulation or exceeds the permitted use, you will need to obtain permission directly from the copyright holder.

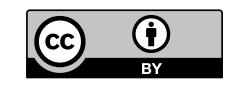

